\title{
Ticagrelor Improves Remodeling, Reduces Apoptosis, Inflammation and Fibrosis and Increases the Number of Progenitor Stem Cells After Myocardial Infarction in a Rat Model of Ischemia Reperfusion
}

\author{
Yochai Birnbaum ${ }^{a, b}$ Dat Tran ${ }^{c}$ Huan Chen ${ }^{d}$ Sven Nylandere Luiz C. Sampaio ${ }^{b}$ \\ Yumei Yed \\ aThe Section of Cardiology, Department of Medicine, Baylor College of Medicine, Houston, Texas,

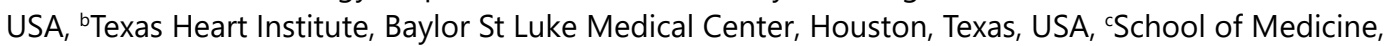 \\ University of Texas Medical Branch, Galveston, Texas, USA, 'The Department of Biochemistry \\ and Molecular Biology, University of Texas Medical Branch, Galveston, Texas, USA, eAstraZeneca \\ Gothenburg, Mölndal, Sweden
}

\section{Key Words}

Apoptosis • Aspirin • Fibrosis • Inflammation • Ischemia-reperfusion • Prasugrel • Remodeling - Stem cells $\cdot$ Ticagrelor

\footnotetext{
Abstract:

Background/Aims: We assessed the effects of ticagrelor, aspirin and prasugrel, started 7days after myocardial ischemia-reperfusion injury on remodeling, inflammation and fibrosis in the rat. We examined whether ticagrelor can affect the number of progenitor cells in the border zone. Ticagrelor, started $24 \mathrm{~h}$ after myocardial ischemia-reperfusion injury, attenuates the decrease in heart function and adverse remodeling, an effect which is blocked by aspirin. Methods: Rats underwent 40min ischemia followed by reperfusion. Oral dosing with vehicle, ticagrelor $(300 \mathrm{mg} / \mathrm{kg} / \mathrm{d})$, aspirin $(20 \mathrm{mg} / \mathrm{kg} / \mathrm{d})$, their combination or prasugrel $(15 \mathrm{mg} / \mathrm{kg} / \mathrm{d})$ started 7 days after infarction. Echocardiography was used to assess systolic function. Heart tissue were analyzed by rt-PCR, immunoblotting, ELISA and immunohistochemistry 2weeks after infarction. Results: Both ticagrelor and aspirin attenuated the decrease in systolic function and remodeling, an effect that was blocked by their combination. Ticagrelor and aspirin attenuated the increase in ANP, BNP, collagen-I and collagen-III. Again, the effect was blocked by their combination. Ticagrelor increased c-Kit, Sca-1, Ki-67, CD34, attenuated the decrease in CD105 mRNA levels, and attenuated the increase in CD31, whereas aspirin increased Ki-67, suppressed the increase in CD31 and attenuated the decrease in CD105 
mRNA levels. Prasugrel did not display any effects. Conclusion: Ticagrelor attenuated adverse remodeling and deterioration of left ventricular systolic function despite starting treatment after the myocardial ischemia-reperfusion injury is completed. Aspirin had similar effects; however, when combined with ticagrelor, the protective effects were significantly attenuated. Ticagrelor increased the levels of several markers of stem cells and regeneration, suggesting cardiac healing by recruiting regenerative cells into the infarct.

(C) 2019 The Author(s). Published by Cell Physiol Biochem Press GmbH\&Co. KG

\section{Introduction}

The PLATelet inhibition and patient Outcomes (PLATO) trial showed that ticagrelor was associated with lower incidence of cardiovascular mortality, myocardial infarction, or stroke compared with the alternative $\mathrm{P}_{2} \mathrm{Y}_{12}$ antagonist clopidogrel in patients with acute coronary syndromes when given on a background therapy of aspirin $[1,2]$. Although the difference was originally ascribed to better and more consistent platelet inhibition than with clopidogrel, it has been speculated that additional benefit of ticagrelor might be provided via an adenosine mediated mechanism [3]. We have previously shown that seven-day oral pretreatment with ticagrelor limits myocardial infarct size (IS) in the rat, whereas clopidogrel was ineffective [4]. This protective effect is dependent on adenosine receptor activation with downstream upregulation and activation of cyclooxygenase-2 [4]. Similar findings have been shown in pigs, where ticagrelor reduced IS measured $24 \mathrm{~h}$ after infarction [5]. In a follow-up study using the same rat model, a single acute administration of ticagrelor just before reperfusion provided a similar reduction in IS following ischemia/reperfusion, as previously seen with longer oral pre-treatment. Again, clopidogrel had no effect [6]. In addition, the reduction in IS translated into an improved heart function 4 weeks later, as assessed by echocardiography [6]. Finally, delayed initiation of oral ticagrelor treatment, started $24 \mathrm{~h}$ after reperfusion, provided a similar improvement in heart function 4 weeks later with limited additional protection when combined with acute pre-treatment [6]. This is intriguing, as most of the ischemia-reperfusion injury is expected to be completed $24 \mathrm{~h}$ after reperfusion. Thus, this delayed ticagrelor treatment could hardly affect reperfusion injury per se. Therefore, the observed improved heart function may rather be related to effects on inflammation, apoptosis and remodeling post infarction. Also, others have shown that the cardioprotective effect of ticagrelor has long-term positive effects on heart function in rat [7] and pig [8] ischemia reperfusion models. In the rat, ticagrelor treatment started after coronary artery ligation and continued after infarction, reduced IS and downregulated mRNA and protein expression of galectin-3, as well as mRNA expression of TNF- $\alpha$ and IL- 6 in the infarct area at $24 \mathrm{~h}, 3$ and 7 days post infarction [7]. In the pig, ticagrelor, but not clopidogrel, started before infarction and continued for 42 days thereafter, reduced myocardial IS and improved long-term remodeling [8]. If these data translate into man, exposure of ticagrelor at the time of primary percutaneous intervention could protect against reperfusion injury and improve long-term heart function. Interestingly, the data indicate that an improved heart function may not exclusively depend on an acute cardioprotective effects, as delayed exposure to ticagrelor also could provide a long-term benefit. Currently, we do not have effective therapy to attenuate scar formation in the infarct zone and prevent progressive fibrosis and adverse remodeling of the non-infarcted zone that lead to progressive heart dysfunction and failure [9], with the exception of aldosterone antagonists. Despite extensive research using pluripotent and stem cell implantation, results have so far been disappointing due to poor engraftment and short survival of the transplanted cells [9-11]. In the current study, we assessed whether ticagrelor, started seven days after myocardial ischemia-reperfusion injury could affect remodeling, inflammation and fibrosis. We also explored the effect of aspirin, an alternative P2Y12 antagonist, prasugrel, and the combination of ticagrelor and aspirin. As we found significant protective effects with aspirin and ticagrelor, we further examined whether these treatments could affect the number of progenitor and stem cells in the border zone of the infarct. 


\section{Cellular Physiology Cell Physiol Biochem 2019;53:961-981 \\ \begin{tabular}{ll|l} 
and Bioche $10.33594 / 000000189$ & (c) 2019 The Author(s). Published by
\end{tabular} \\ Published online: 11 December 2019 Cell Physiol Biochem Press GmbH\&Co. KG \\ Birnbaum et al.: Ticagrelor Improves Remodeling After Myocardial Infarction}

\section{Materials and Methods}

\section{Materials}

Wild-type Sprague-Dawley rats were purchased from Charles River Laboratories (Wilmington, MA). Ticagrelor was provided by AstraZeneca. Aspirin and prasugrel were purchased from Sigma.

Mouse C-Reactive Protein/CRP ELISA Kit was purchased from R\&D systems. Myocardial $\mathrm{PGE}_{2}$, 6-keto-PGF ${ }_{1 \alpha}$ and 15-epi-lipoxin $\mathrm{A}_{4}$ ELISA kits were purchased from Cayman Chemical. TRIzol reagent was purchased from Invitrogen, Carlsbad, CA. Anti-Ki-67, c-Kit, anti-Oct4 and anti-Sca-1 antibodies for the immunoblotting were purchased from Santa Cruz Biotechnology and anti- $\beta$-actin from Sigma-Aldrich. Anti-CD31, anti-Ki-67, anti-CD105, anti-Sca-1 and anti-Nkx2.5 antibodies for the immunohistochemistry were purchased from Abcam. Anti-CD 31 http://www.abcam.com/cd31-antibody-tld-3a12-ab64543. htmland anti-c-Kit antibodies for the immunofluorescence staining were purchased from Abcam and the fluorescence-labeled secondary antibodies (AlexaFluor 488 for CD31 and AlexaFluor 546 for c-Kit) were purchased from Invitrogen.

\section{Surgery}

All animal care and experiments were conformed to the "Position of the American Heart Association on Research Animal Use," adopted by the AHA on November 11, 1984 and the Guide for the Care and Use of Laboratory Animals, published by the National Institutes of Health (NIH Publication No. 85-23, revised 1996) and approved by the Institutional Animal Care and Use Committee of the University of Texas Medical Branch, Galveston, Texas. Experiments were conducted according to recent published guidelines for experimental models of myocardial ischemia and infarction and cardioprotection [12, 13]. Rats were anesthetized with ketamine-xylazine and ventilated. Isofluorane (1-2.5\% titrated to effect) was added to maintain anesthesia using a volume-controlled ventilator (Harvard Apparatus). The left coronary artery (LCA) was ligated with 6-0 polypropylene (Ethicon, Inc.) at the level of the edge of the left atrial appendage for $40 \mathrm{~min}$ followed by reperfusion. Ischemia was verified by a change in the color of the myocardium and reperfusion by return of color. The rats were returned to the cages for recovery after chest and skin closure. Therapy was initiated on the $7^{\text {th }}$ day after surgery. Animals were sacrificed either 2 weeks after infarction for ELISA, rt-PCR, immunoblotting and histology of heart tissue and plasma biomarkers or 4 weeks after infarct for heart weight measurement. Platelet aggregation was assessed 4 weeks after infarction.

Treatment: Group 2-6 had surgery and ischemia-reperfusion, whereas group 1 only had sham surgery (encircling the coronary artery with the 6-0 polypropylene without induction of ischemia).

1. Sham: vehicle (normal chow).

2. Control (Cont): vehicle (normal chow).

3. Ticagrelor: Ticagrelor $300 \mathrm{mg} / \mathrm{kg} / \mathrm{d}$.

4. Aspirin: Aspirin $20 \mathrm{mg} / \mathrm{kg} / \mathrm{d}$.

5. Ticagrelor + Aspirin: Ticagrelor $300 \mathrm{mg} / \mathrm{kg} / \mathrm{d}+\operatorname{aspirin} 20 \mathrm{mg} / \mathrm{kg} / \mathrm{d}$.

6. Prasugrel: Prasugrel $15 \mathrm{mg} / \mathrm{kg} / \mathrm{d}$.

Ticagrelor, aspirin and prasugrel were mixed with normal chow. Tissue samples taken from the myocardium of the anterior left ventricular wall at the border zone of infarction 2 weeks after infarct were subjected to immunoblotting, RT-PCR and histology.

\section{Echocardiography}

Trans-thoracic echocardiography was performed under anesthesia with ketamine-xylazine at baseline, before surgery, and 1, 14 and 28d after surgery using Vevo 770 ultrasound machine equipped with a 25 MHz transducer-710B (Visualsonics-Toronto, Canada). Standard M-mode images were taken in the longand short-axis position at the level of the papillary muscles for each animal. Left ventricle internal diameters at end diastole (LVIDd) and systole (LVIDs) and left ventricular fractional shortening (FS) were measured. Left ventricular end diastolic (LVEDV) and end systolic (LVESV) volumes and left ventricle ejection fraction (LVEF) were measured by a single-plane area length method using 2D parasternal long axis images [6]. 


\section{Cellular Physiology Cell Physiol Biochem 2019;53:961-981 \\ \begin{tabular}{l|l|l}
\hline DOI: 10.33594/000000189 & ( 2019 The Author(s). Published by
\end{tabular} \\ and BiOChemistry Published online: 11 December 2019 Cell Physiol Biochem Press GmbH\&Co. KG \\ Birnbaum et al.: Ticagrelor Improves Remodeling After Myocardial Infarction}

\section{Platelet aggregation}

Platelet-rich plasma (PRP) was prepared from blood samples collected at 28 days after infarct by centrifugation of whole blood anticoagulated with citrate dextrose at $800 \mathrm{rpm}$ for 10 minutes at room temperature. Platelet aggregation were recorded after activation with $15 \mu \mathrm{M}$ ADP using a platelet aggregation profiler (PAP-8; BioData). Data are expressed as the final percent aggregation response after 6 min $[4,6]$.

\section{Enzyme-linked Immunosorbent Assay (ELISA)}

Myocardial samples were homogenized and prepared in RIPA buffer (Sigma-Aldrich) containing protease and phosphatase inhibitors (Roche Diagnostics). The supernatants of the tissue lysate were collected, and protein concentration was determined by the Bradford method. Blood samples were collected using EDTA as an anticoagulant, and plasma samples were centrifuge for 15 minutes at $1000 \times \mathrm{xg}$ at $2-8^{\circ} \mathrm{C}$ within 30 minutes of collection. C-reactive protein (CRP) in plasma was measured using Mouse C-Reactive Protein/CRP ELISA Kit. Myocardial PGE ${ }_{2}, 6$-keto-PGF ${ }_{1 \alpha}$ and 15-epi-lipoxin $\mathrm{A}_{4}$ were determined using ELISA kits. The absorbance was recorded at $450 \mathrm{~nm}$ with a plate reader $[4,6]$.

\section{Gene Expression Analysis by RT-PCR}

Total RNA was extracted from the myocardial samples using TRIzol reagent according to the protocol per manufacturer's instruction. Two $\mu \mathrm{g}$ of total RNA from each sample was reverse-transcribed into cDNA. Equal amounts of the reverse transcriptional products were subjected to PCR amplification for gene expression analyses as previously described. Primers and probes for rat GAPDH, ANP, BNP, collagen I, collagen III, $\alpha$-MHC, c-Kit, Sca-1. Ki-67+, CD34, CD31, CD133, CD146 and CD105 were synthesized and analyzed (Table 1). The Ct (threshold cycle) is defined as the number of cycles required for the fluorescence signal to exceed the detection threshold. Expression of the gene relative to the GAPDH was calculated as the difference between the threshold values of these two genes $\left(2^{-\Delta c t}\right)$. Melting curve analysis was performed during real-time PCR to analyze and verify the specificity of the reaction. The values are given as the means \pm standard error of the mean (SER) of four independent experiments. Each sample was analyzed in triplicate and normalized by GAPDH.

\section{Immunoblotting}

Myocardial tissue samples were homogenized in lysis buffer (in mM): 25 Tris $\cdot \mathrm{HCl}(\mathrm{pH}$ 7.4), 0.5 EDTA, 0.5 EGTA, 1 phenylmethylsulfonyl fluoride, 1 dithiothreitol, $25 \mathrm{NaF}, 1 \mathrm{Na}_{3} \mathrm{VO}_{4}, 1 \%$ Triton $\mathrm{X}-100,2 \%$ SDS and $1 \%$ protease inhibitor cocktail. Concentration of protein was determined by the Bradford method and protein were separated on gradient $4-12 \%$ Bis-Tris NuPAGE gels. Protein $(50 \mu \mathrm{g})$ was fractionated by SDS-PAGE (4\%-20\% polyacrylamide gels) and transferred to PVDF membranes (Millipore, Bedford, MA). Membranes were blocked with non-fat $5 \%$ dry milk in room temperature and incubated over-night $\left(4^{\circ} \mathrm{C}\right)$ with anti-Ki- 67 , anti-c-Kit, anti-Oct 4 or anti-Sca- 1 antibodies. $\beta$-actin was used as a loading control. The membranes were then washed and incubated with secondary HRP-conjugated antibodies for $1 \mathrm{~h}$ at room temperature. Bound antibodies were detected using the chemiluminescent substrate (NEN Life Science Products, Boston, MA). The protein signals were quantified with an image-scanning densitometer, and the strength of each protein signal was normalized to the corresponding $\beta$-actin signal. Data are expressed as percent relative the expression in the Sham group.

Table 1. List of PCR primer used for the experiments

\section{Histology}

Four $\mu \mathrm{m}$ thickness sections from the left ventricular border zone of the infarction were fixed in $10 \%$ buffered formaldehyde for $24 \mathrm{~h}$ and embedded in paraffin.

\begin{tabular}{lll}
\hline Target mRNA & Forward primer & Reverse primer \\
\hline ANP & AGCATGGGCTCCTTCTCC & GTCAATCCTACCCCGAAGCAGCT \\
BNP & CCATCGCAGCTGCCTGGCCCATCACTTCTG & GACTGCGCCGATCCGGTC \\
$\alpha-\mathrm{MHC}$ & TCCAGAGGCCAGTACACTT & ACCTTGTTAAACAGCTGGGGT \\
c-Kit & CTAGCCAGAGACATCAGGA & CCATAGGACCAGACATCAC \\
CD31 & GCTGTCTACTCAGTCATGGCC & CGTCTCTTTCCTTCTGGATGGTG \\
CD133 & CCAGCGGCAGAAGCAGAACGA & GTCAGGAGAGCCCGCAAGTCT \\
CD34 & GCGAGGCTTTCAACACAACC & ACTCCACTGTCTTGATTCCC \\
CD146 & CAGTCAGTCCTCACAGCAGA & TCTCCTGTTTTCCTGAGCGT \\
CD105 & GGCAGCTTCAACAACCATCA & GGATGGACTAGATCGGAGCC \\
CD44 & TGGATCCGAATTAGCTGGAC & GCTTCTTCTTCTGCCCACAC \\
Ki-67 & ATTCAGTTCCGCCAATCC & GGCTTCCGTCTTCATACCTAAA \\
Sca-1 & CGGTCATTCAGACCACACACAG & TGGGTTGAAGTTCTC GCTCTTG \\
Collagen I & ATCAGCCCAAACCCCAAGGAGA & CGCAGGAAGGTCAGCTGGATAG \\
Collagen III & GACAGATGCTGGTGCTGAGAAG & TCTGAGGAAGGCCAGCTGTAC \\
GAPDH & ATGATTCTACCCACGGCAAG & CTGGAAGATGGTGATGGGTT \\
\hline
\end{tabular}




\section{Cellular Physiology Cell Physiol Biochem 2019;53:961-981 \\ \begin{tabular}{ll|l} 
DOI: 10.33594/000000189 & (c) 2019 The Author(s). Published by
\end{tabular} \\ Published online: 11 December 2019 Cell Physiol Biochem Press GmbH\&Co. KG \\ Birnbaum et al.: Ticagrelor Improves Remodeling After Myocardial Infarction}

Tissue sections were stained with haematoxylin and eosin (H\&E) and Masson's trichrome [14]. The cardiomyocytes are stained red and fibrosis stained blue. Fibrosis was quantified at a final magnification of $\times 400$ with a microscope (Olympus DP71). Percent fibrosis area was analyzed using Image J analysis software, expressed as percentage of fibrosis area to the total area of each microscopic field. Eight microscopic fields of each sample were analyzed.

\section{Apoptosis}

Tissue sections from the border zone of infarction were fixed and embedded in paraffin, and apoptotic cells were detected by labeling DNA strand breaks using terminal deoxynucleotidyl transferase-mediated dUTP-biotin nick end labeling (TUNEL) method [6]. The total number of positive nuclei was determined by counting all the labeled nuclei present in the entire area. Ten areas were randomly selected. The apoptotic index was expressed as the ratio of positively stained nuclei to total nuclei. Images were obtained using Olympus IX71 microscope at a magnification of $\times 20$.

\section{Immunohistochemistry}

Tissue sections were fixed in $4 \%$ formalin and embedded in paraffin. Non-specific staining between primary antibodies and tissue were blocked by incubating in blocking buffer at room temperature. Primary antibodies (anti-CD31, anti-Ki-67, anti-CD105, anti-Sca-1 or anti-Nkx2.5) were then applied according to manufacturer's instructions. The sample sections were washed and then incubated with secondary antibody according to the manufacturer's instructions.

\section{Immunofluorescence Staining}

Hearts were freeze-sectioned into 4-mm-thick-sections and fixed in 4\% formaldehyde. Myocardial sections were incubated with blocking buffer (1X PBS/5\% normal serum/0.3\% Triton ${ }^{\mathrm{TM}} \mathrm{X}-100$ ). Anti-CD 31 http://www.abcam.com/cd31-antibody-tld-3a12-ab64543.htmland anti-c-Kit antibodies were applied to the sections followed with the fluorescence-labeled secondary antibodies. AlexaFluor 488 for CD31 and AlexaFluor 546 for c-Kit were used for visualization in the fluorescence microscope (Olympus IX71). Diamidino-2-phenylindole (DAPI) were used to stain the nuclei in the mounting medium. As positive controls for c-Kit we used adult rat spleen. As negative controls, the section sample staining was only performed with secondary antibody. To test for auto fluorescence, staining was performed without both primary and secondary antibodies. Sections were then mounted with an anti-fade mounting media and visualize using a fluorescence microscope. The relative number of cells expressing CD31 or c-Kit were counted in each field. Slides ( 6 hearts from each group) were counted at $40 \mathrm{x}$ magnification.

\section{Statistical analysis}

Data are presented as means \pm SER. Analysis of variance (ANOVA) with Sidak correction for multiple comparisons was applied to compare the different groups. Values of $\mathrm{P}<0.05$ were considered statistically significant.

\section{Results}

During follow up 4 rats died, 2 in the control group, 1 in the ticagrelor+aspirin group and 1 in the prasugrel group. A total of 8,6,8, 8, 7, and 7 animals were analyzed at day 28 in the sham, control, ticagrelor, aspirin, ticagrelor+aspirin and prasugrel groups, respectively.

At day 28 there were no differences in body weight (Fig. 1a) or heart rate (Fig. 1b) among the groups.

Heart weight (absolute weight (Fig. 1c) or adjusted for tibial length (Fig. 1d)) significantly increased in the control group compared to the sham group. Ticagrelor and aspirin equally attenuated the increase. However, combining ticagrelor with aspirin completely blocked the effect on heart weight. Prasugrel did not affect heart weight.

ADP-induced platelet aggregation at day 28 was comparable between the sham and control group (Fig. 1e). Ticagrelor, aspirin, ticagrelor+aspirin and prasugrel equally reduced platelet aggregation without differences among these groups. 


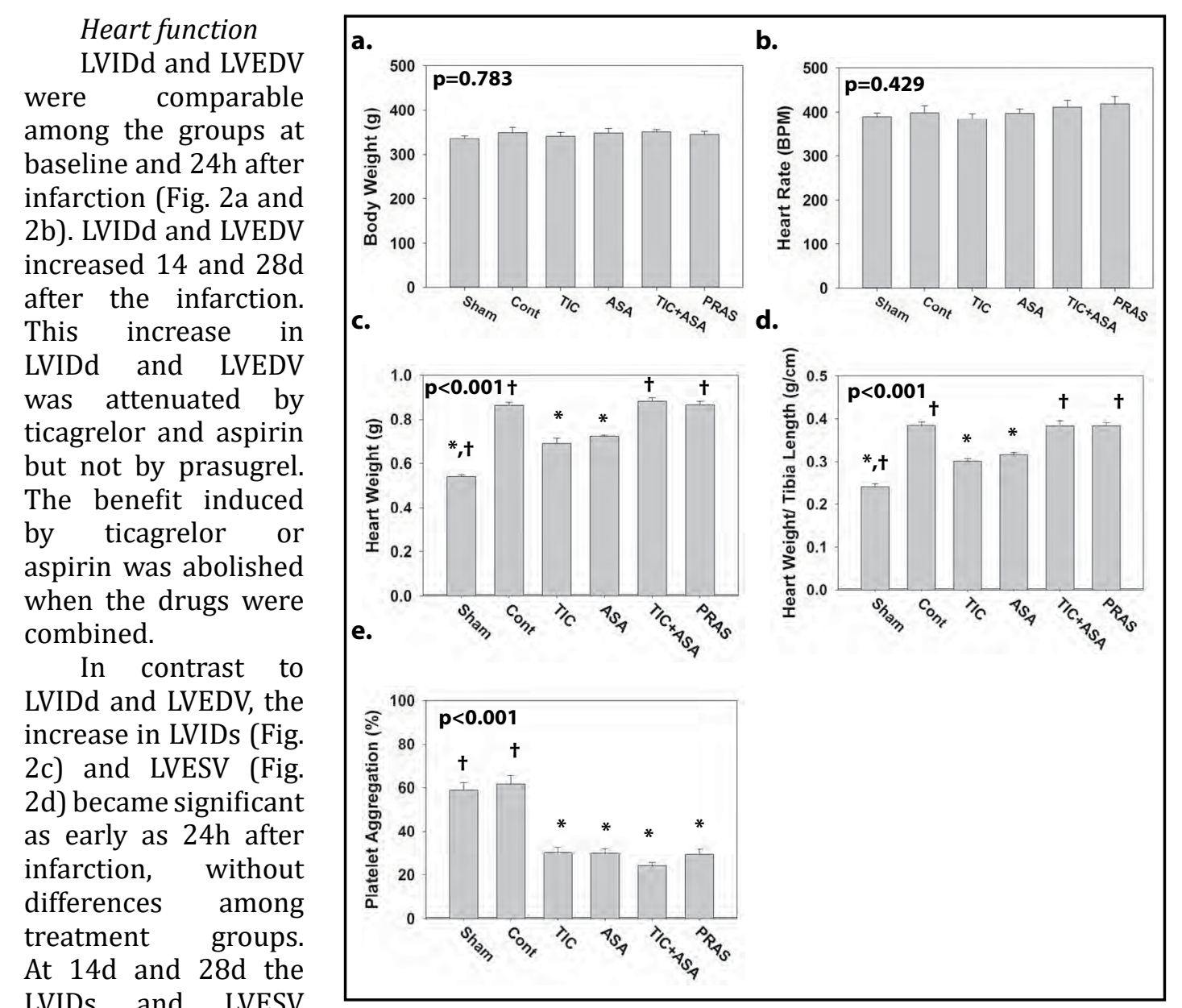
LVIDs and LVESV increase, induced by the infarction, was attenuated by ticagrelor and aspirin, whereas prasugrel was ineffective. The benefit effect induced by ticagrelor or aspirin. was abolished when both drugs were combined.

LVEF was decreased $24 \mathrm{~h}$ after infarction, without significant differences among the groups (Fig. 2e). At $14 \mathrm{~d}$ and $28 \mathrm{~d}$ the decrease in LVEF was significantly attenuated by ticagrelor and aspirin, whereas prasugrel had no effect. The benefit induced by ticagrelor or aspirin was abolished when the two drugs were combined.

Thus, the effects of ticagrelor and aspirin on the parameters of remodeling and LVEF were comparable at all time points. However, when combined, the effects were attenuated.

\section{ELISA}

Myocardial levels of 6-keto-PGF ${ }_{1 \alpha}$ in the remote non-ischemic zone were not affected by the infarction but were increased by ticagrelor, whereas aspirin and prasugrel had no effect (Fig. 3a). The increase induced by ticagrelor was completely blocked when combined with aspirin. On the other hand, myocardial levels of 6-keto-PGF ${ }_{1 \alpha}$ in the border zone of the infarct increased after infarction (Fig. 3b). Aspirin abolished this increase, whereas ticagrelor induced a non- significant increase, which was completely blocked by aspirin in the combination group. Prasugrel had no effect on 6-keto-PGF ${ }_{1 \alpha}$ levels in the border zone of the infarction. 
Fig.2.Echocardiographic findings. A total of 8,6 , $8,8,7$, and 7 animals were analyzed at day 28 after surgery for the Sham, Control, TIC, ASA, TIC+ASA and PRAS groups, respectively. a. Left ventricular internal diameter in diastole (LVIDD); b. Left ventricular end diastolic volume (LVEDV); c. Left ventricular internal diameter in systole (LVIDS); d. Left ventricular end systolic volume (LVESV); e. Left ventricular ejection fraction (LVEF). LVIDD were comparable among the groups at baseline and $24 \mathrm{~h}$ after infarction $\quad(p=0.851)$. LVIDD increased in the Control group compared to the Sham group at $14 \mathrm{~d}(\mathrm{p}<0.001)$ and $28 \mathrm{~d} \quad(\mathrm{p}<0.001)$ after infarction. At $14 \mathrm{~d}$ and 28d, LVIDD was significantly smaller in the TIC $(\mathrm{p}<0.001$ and $\mathrm{p}<0.001$ ) and ASA

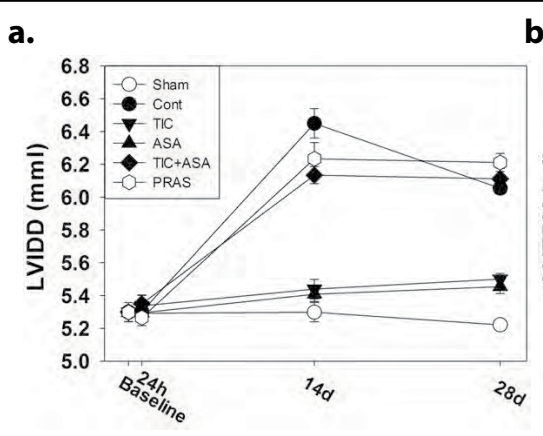

c.

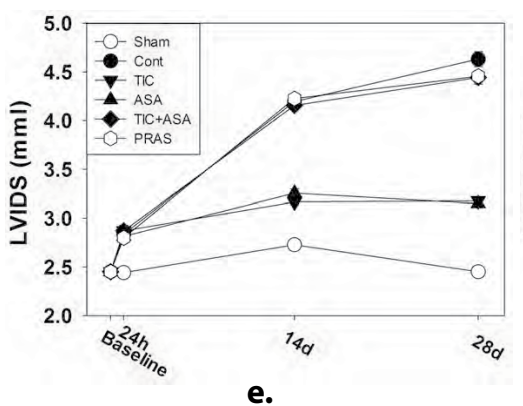

d.
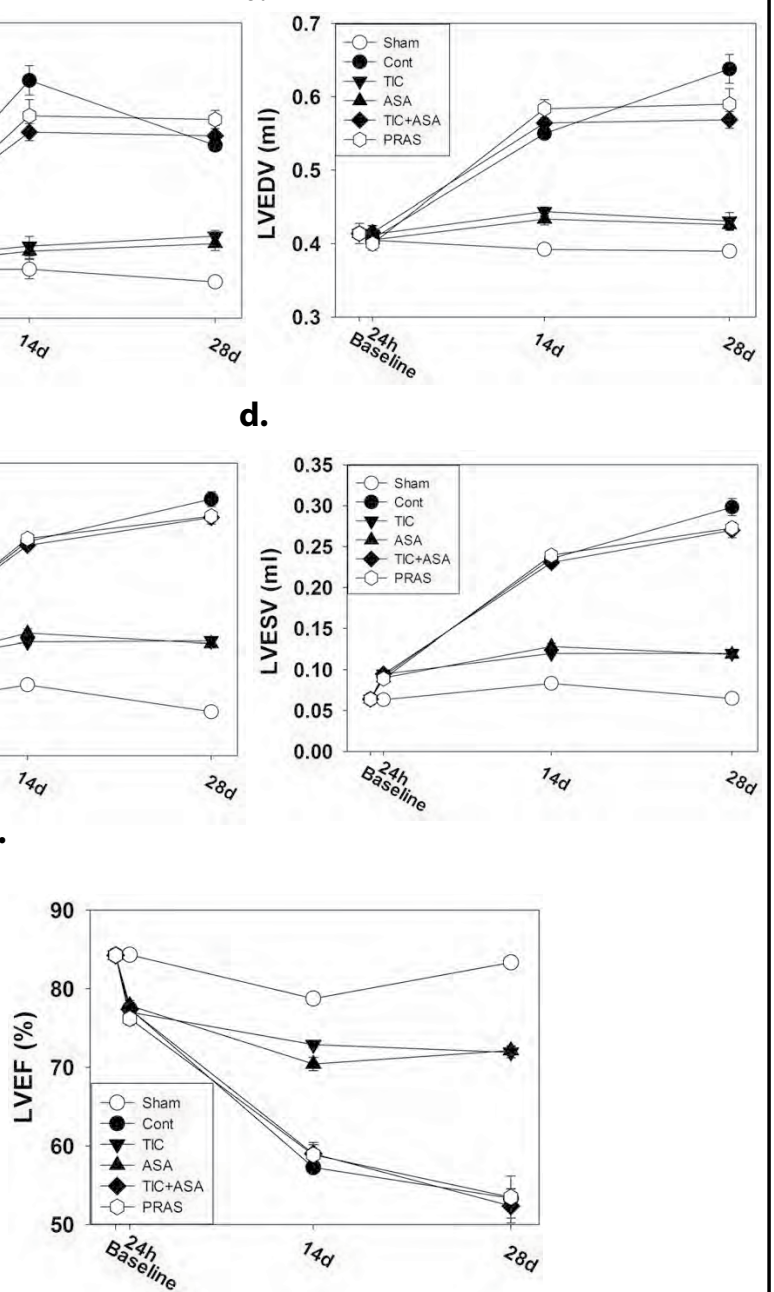

$(\mathrm{p}<0.001$ and $\mathrm{p}<0.001)$ groups than in the Control group. However, the increase in LVIDD over time was not affected by TIC+ASA ( $\mathrm{p}=0.051$ and $\mathrm{p}=0.999$, respectively) or PRAS ( $\mathrm{p}=0.455$ and $\mathrm{p}=0.186$, respectively). ASA- aspirin; Cont- control; PRAS- prasugrel; TIC- ticagrelor. No significant differences were seen in the LVEDV among the groups at baseline and at $24 \mathrm{~h}$ after infarction $(\mathrm{p}=0.844)$. LVEDV significantly increased in the Control group compared to the Sham group at $14 \mathrm{~d}$ and $28 \mathrm{~d}(\mathrm{p}<0.001$ and $\mathrm{p}<0.001)$. The increase was attenuated by TIC ( $p<0.001$ and $p<0.001$ vs. control) and ASA ( $p<0.001$ and $p<0.001$ vs. control), but to a lesser extent with TIC+ASA ( $p=0.993$ and $p=0.022)$ and not at all with PRAS ( $p=0.160$ and $p=0.291)$. At $24 \mathrm{~h}$ after infarction, LVIDS increased in all groups subjected to infarction, without differences among groups. However, at $14 \mathrm{~d}$ and $28 \mathrm{~d}$ the increase in LVIDS was attenuated in the TIC $(\mathrm{p}<0.001 ; \mathrm{p}<0.001)$ and ASA $(p<0.001 ; p<0.001)$ compared to the Control group, whereas TIC+ASA ( $=1.00 ; p=0.287)$ and PRAS $(p=1.00 ; p=0.391)$ had no effect. At $24 \mathrm{~h}$ after infarction LVESV increased in all groups exposed to infarct compared to the Sham group, without significant differences among these five groups. However, at $14 \mathrm{~d}$ and $28 \mathrm{~d}$ the increase in LVESV was significantly attenuated in the TIC $(p<0.001 ; p<0.001)$ and ASA $(p<0.001$; $\mathrm{p}<0.001)$, but not the TIC+ASA $(\mathrm{p}=0.999 ; \mathrm{p}=0.068)$ and PRAS $(\mathrm{p}=1.00 ; \mathrm{p}=0.143)$ groups. A decrease in LVEF was noticed $24 \mathrm{~h}$ after infarction in all the five groups subjected to infarction compared to the Sham group, without significant differences among them. At $14 \mathrm{~d}$ and $28 \mathrm{~d}$ the decrease in LVEF was significantly attenuated in the TIC $(\mathrm{p}<0.001 ; \mathrm{p}<0.001)$ and ASA $(\mathrm{p}<0.001 ; \mathrm{p}<0.001)$, but not in the TIC+ASA $(\mathrm{p}=0.965$; $\mathrm{p}=1.00)$ and PRAS ( $=0.978 ; \mathrm{p}=1.00)$. 
Myocardial $\mathrm{PGE}_{2}$ levels remained unchanged in the remote non-ischemic zone after infarction (Fig. 3c). These levels were increased by ticagrelor, whereas aspirin and prasugrel had no effect. The increase induced by ticagrelor was completely blocked by aspirin. On the other hand, infarct significantly increased $\mathrm{PGE}_{2}$ levels in the border zone (Fig. 3d). These levels were reduced by aspirin, whereas ticagrelor and prasugrel had no effect. The reduction induced by aspirin was not affected by ticagrelor.

Infarction did not affect myocardial levels of 15-epi-lipoxin $\mathrm{A}_{4}$ in both the remote and ischemic zone. Ticagrelor alone and aspirin alone significantly increased myocardial levels of 15-epi-lipoxin $A_{4}$ (Fig. $3 e$ and f), whereas the increase was completely blocked when aspirin and ticagrelor were combined. Prasugrel had no effect on myocardial 15-epi-lipoxin $\mathrm{A}_{4}$ levels.

The infarction induced an increase in the plasma CRP levels (Fig. 3e). The levels were equally attenuated by ticagrelor and aspirin, whereas prasugrel had no effect. The reduction induced by ticagrelor or aspirin was blocked when both drugs were combined.

\section{Rt-PCR}

Myocardial $\alpha$-MHC mRNA levels were unaffected after infarction (Fig. 4a). The levels were increased by ticagrelor and non-significantly increased by aspirin, whereas prasugrel had no effect. The increase induced by ticagrelor or aspirin was abolished when both drugs were combined.

Myocardial ANP (Fig. 4b) and BNP mRNA levels (Fig. 4c) both increased after infarction. This increase was attenuated by ticagrelor and aspirin, whereas prasugrel had no effect. Again, the increase induced by ticagrelor or aspirin was blocked when both drugs were combined.

Fig. 3. Tissue levels of $6-\mathrm{Keto}^{-\mathrm{PGF}_{1 \alpha}}$ in the remote, non-ischemic zone (a) and postischemic zone (b) 14 days after infarction. Tissue levels of $\mathrm{PGE}_{2}$ in the remote, nonischemic zone (c) and post-ischemic zone (d). Tissue levels of 15 -epilipoxin $\mathrm{A}_{4}$ in the remote, non-ischemic zone (e) and post-ischemic zone (f). g. Plasma levels of C-reactive protein (CRP). There were 6 animals in each group. $* \mathrm{p}<0.001$ vs. Cont. $\dagger p<0.002$ vs. TIC. ASA- aspirin; Contcontrol; PRAS- prasugrel; TIC- ticagrelor.

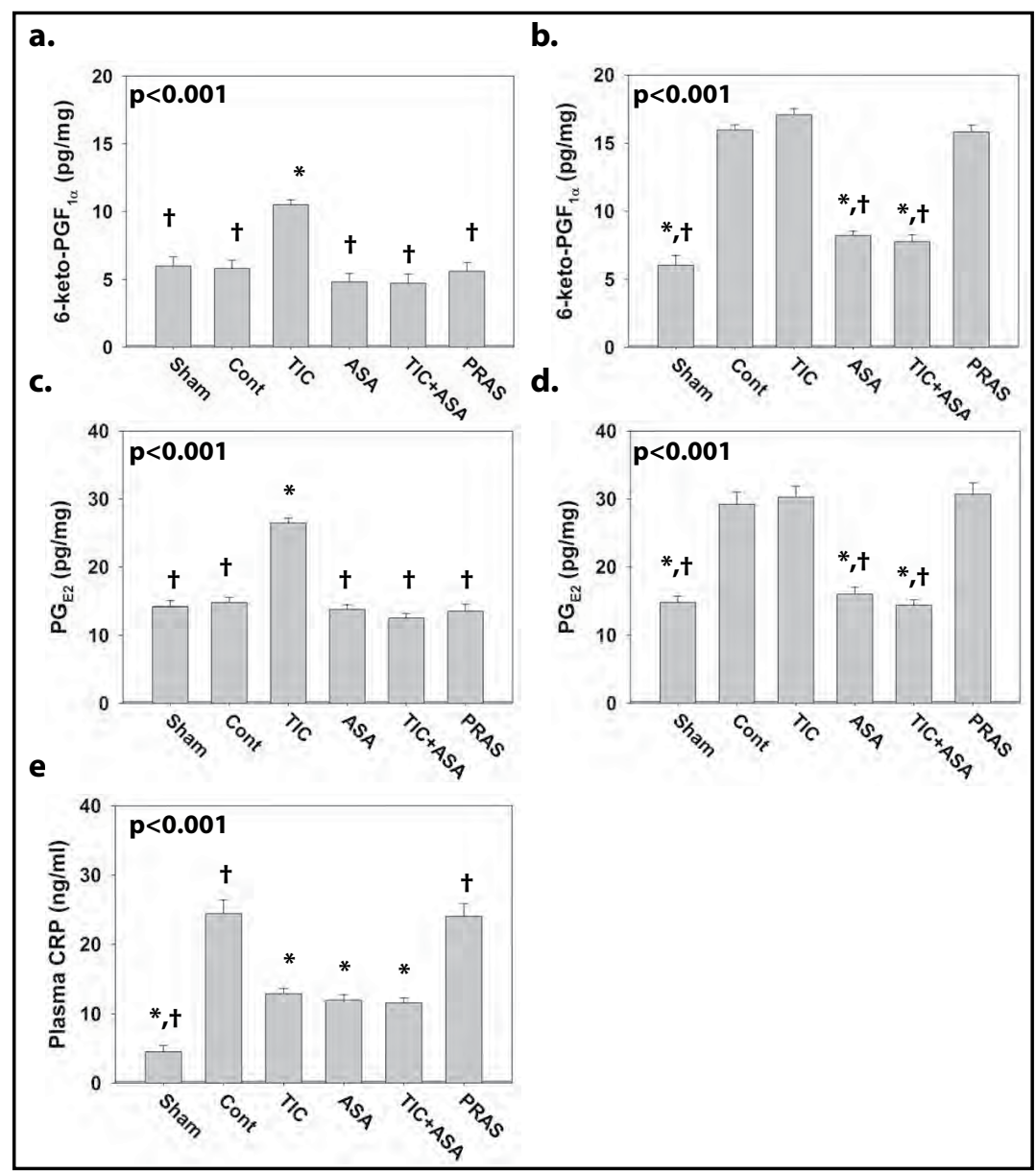


Myocardial collagen-I (Fig. 4d) and collagen-III (Fig. 4e) mRNA levels were both increased after infarction. This increase was attenuated by ticagrelor and aspirin, whereas prasugrel had no effect. Once more, the increase induced by ticagrelor or aspirin was blocked when both drugs were combined.

Myocardial c-Kit (Fig. 5a), Sca-1 (Fig. 5b), Ki-67 (Fig. 5c), CD34 (Fig. 5e), CD133 (Fig. 5f), CD44 (Fig. 5g) and CD146 mRNA levels (Fig. 5i) were not affected by the infarction, whereas CD31 mRNA levels increased (Fig. 5d) and CD105 mRNA levels decreased (Fig. 5h) 14 days after infarction. Ticagrelor increased c-Kit, Sca-1, Ki-67, CD34, attenuated the decrease in CD 105 mRNA levels, and attenuated the increase in CD31. Aspirin increased Ki-67, suppressed the increase in CD31 and, similar to ticagrelor, attenuated the decrease in CD105 mRNA levels. The increase induced by ticagrelor on c-Kit, Sca-1 and CD34 mRNA levels was attenuated in combination with aspirin. The effect of ticagrelor+aspirin on Ki67 mRNA levels tended to be attenuated compared to the effects of ticagrelor alone and aspirin alone $(p=0.757)$. The effect of ticagrelor+aspirin on CD105 levels was significantly attenuated compared to the effects of ticagrelor alone and aspirin alone. CD133, CD44 and CD146 mRNA levels were unaffected by infarction and treatments. Prasugrel had no effect on any of these mRNA levels.

Fig. 4. mRNA levels in the border zone 14 days after infarction (7 days after starting therapy). a. $\alpha$-myosin Heavy Chain ( $\alpha$-MHC); b. Atrial Natriuretic Peptide (ANP); c. Brain Natriuretic Peptide (BNP); d. Collagen-I; e. Collagen-III. There were 4 samples in each group. * $\mathrm{p}<0.002$ vs. Cont. $\dagger \mathrm{p}<0.003$ vs. TIC. ASA- aspirin; Contcontrol; PRAS- prasugrel; TIC- ticagrelor.

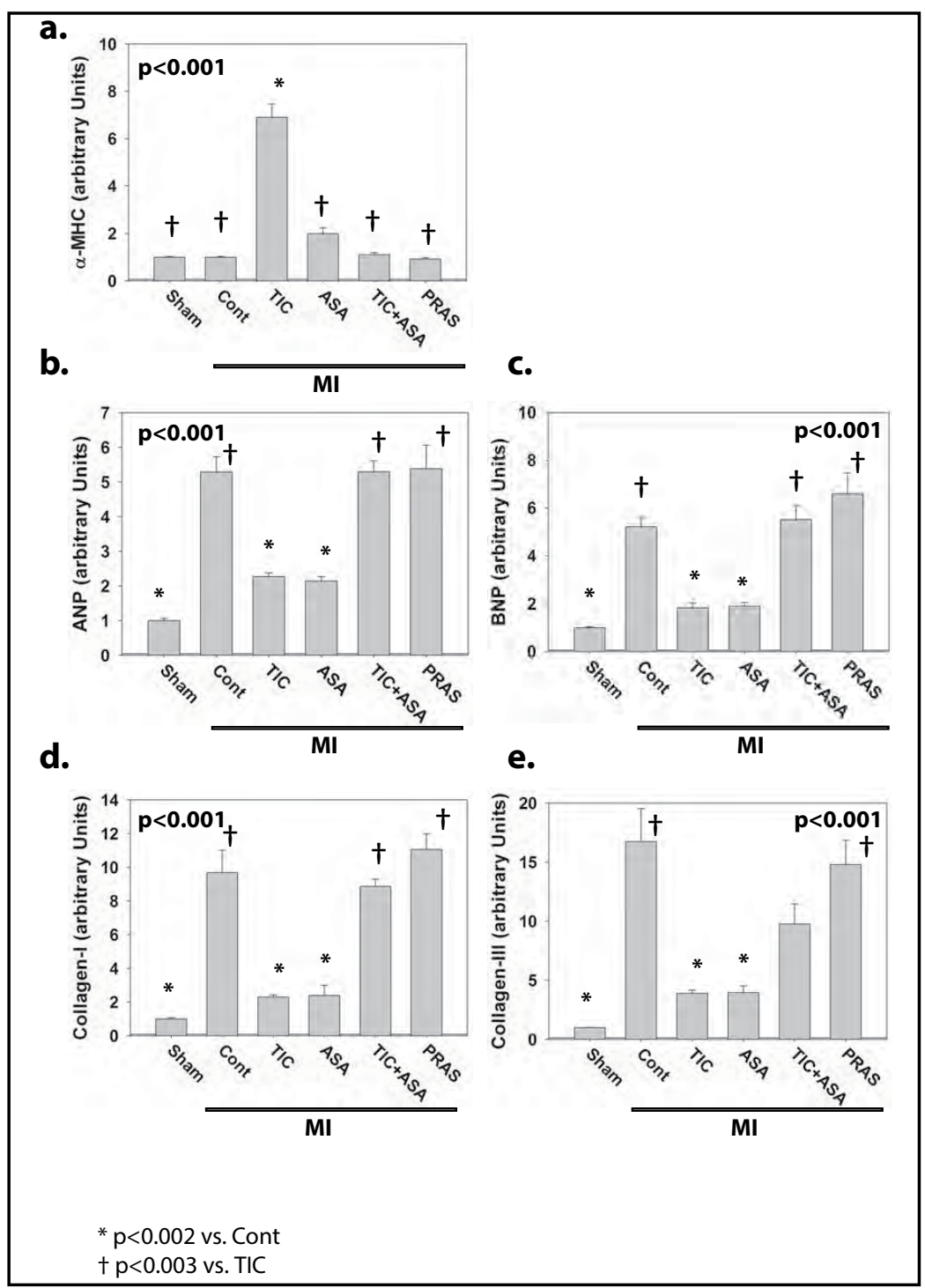


Immunoblotting

Myocardial c-Kit levels increased after infarction (Fig. 6a and b). Ticagrelor significantly increased the levels, whereas aspirin and prasugrel had no effect. Aspirin completely blocked the effect of ticagrelor. Ki-67 levels were not affected by infarction (Fig. 6a and c). Ticagrelor and aspirin significantly increased the levels, whereas prasugrel had no effect. The effect of ticagrelor was more pronounced compared to aspirin and was attenuated when aspirin and ticagrelor were combined. Infarct increased Oct4 levels (Fig. 6a and d). Only ticagrelor, but not aspirin or prasugrel further increased Oct4 levels in animals after myocardial infarction. Aspirin completely blocked the effect of ticagrelor. Infarct did not alter Sca-1 levels. Ticagrelor significantly increased Sca-1 levels, whereas aspirin and prasugrel had no effect. Aspirin attenuated the effect of ticagrelor (Fig. 6a and e).

\section{Histology and Immunohistochemistry}

As expected, the percent of TUNEL positive cells (Fig. 7a and c) and extent of fibrosis (Fig. $7 \mathrm{~b}$ and c) increased 14 days after infarction. Both ticagrelor and aspirin attenuated the increase. However, when combined, the protective effect was attenuated. On the other hand, prasugrel had no effect on apoptosis and fibrosis.

The number of Ki-67 positive cells was higher in the border zone after infarction (Fig. 8b). Ticagrelor and aspirin significantly increased the number of the Ki-67 positive cells with a non-significant reduction when combined. Prasugrel had no effect.

The staining volume of Nkx2.5 significantly increased in the border zone after infarction compared to the sham group (Fig. 8c). Ticagrelor and aspirin increased the staining volume

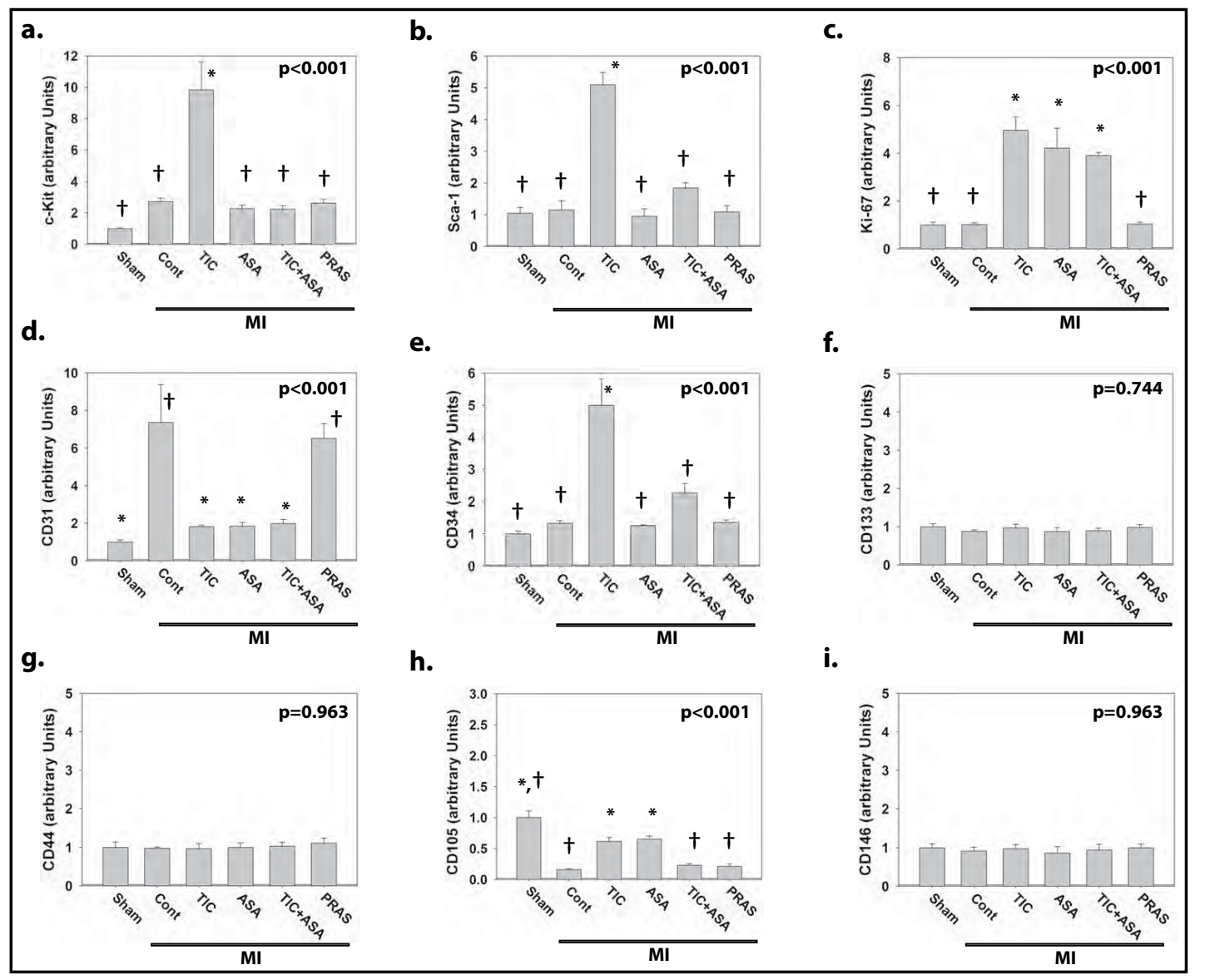

Fig. 5. mRNA levels in the border zone 14 days after infarction (7 days after starting therapy). a. c-KIT; b. Sca-1; c. Ki-67; d. CD31; e. CD34; f. CD133; g. CD44; h. CD105; i. CD146. There were 4 samples in each group. $* \mathrm{p}<0.008$ vs. Cont. $\dagger \mathrm{p}<0.03$ vs. TIC. ASA- aspirin; Cont- control; PRAS- prasugrel; TIC- ticagrelor. 
Fig. 6. samples of immunoblots (a.) and densitometric analyses of myocardial c-Kit (b.), Ki-67 (c.), Oct4 (d.), and Sca-1 (e.) at the border zone 14 days after infarction (7 days after starting therapy). There were 4 samples in each group. ${ }^{*} \mathrm{p}<0.016$ vs. Cont. $\dagger \mathrm{p}<0.001$ vs. TIC. ASA- aspirin; Contcontrol; PRAS- prasugrel; TIC- ticagrelor.

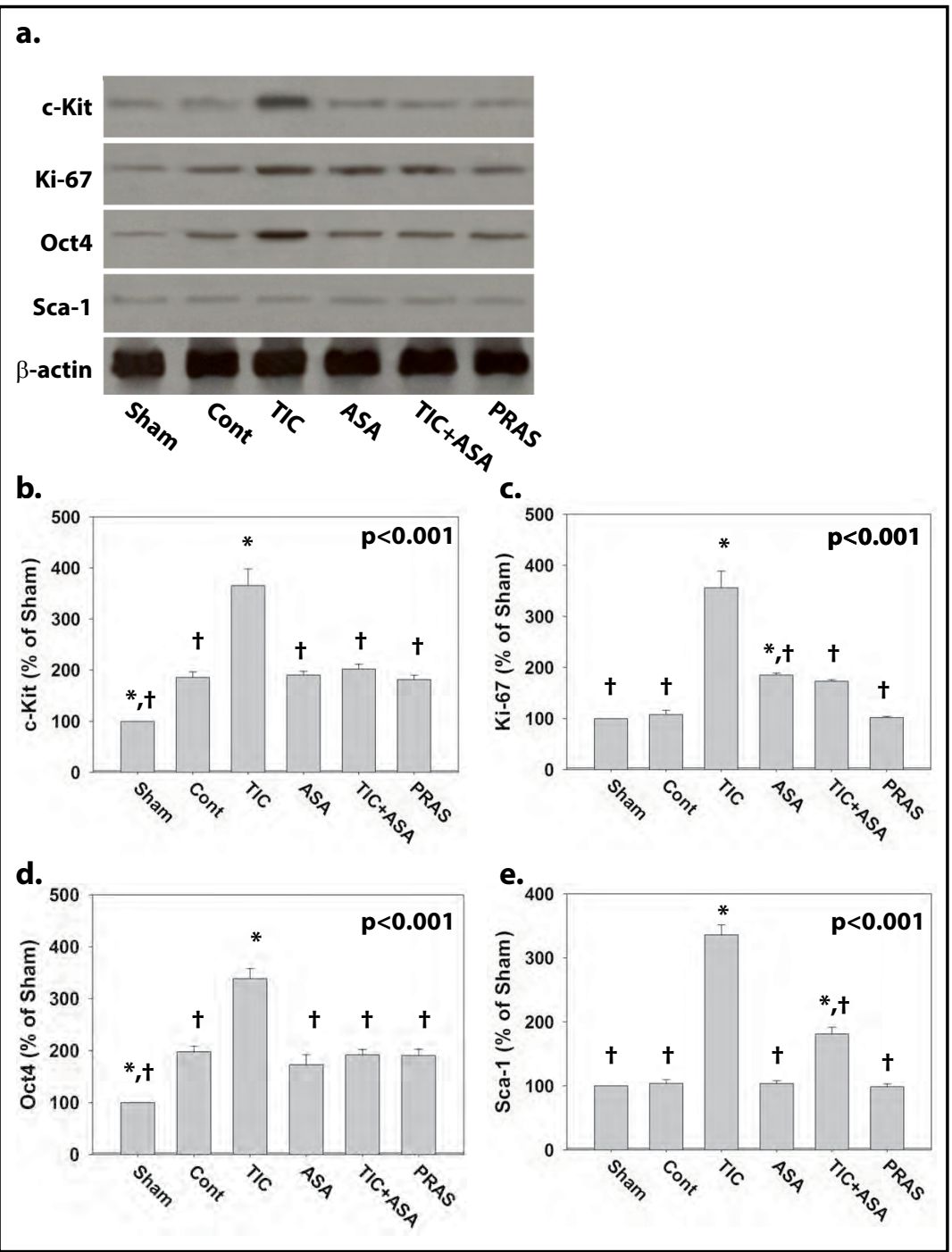

of NKx2.5, without a significant difference between the treatments. Yet, the increase was significantly attenuated in the ticagrelor+aspirin group compared to ticagrelor $(\mathrm{p}<0.001)$ or aspirin alone $(\mathrm{p}<0.001)$ groups. Once more, prasugrel had no effect.

There was no increase in the number of Sca-1 positive cells 14 days after infarction (Fig. 9a and b). Ticagrelor, but not aspirin or prasugrel increased the concentration of Sca-1 positive cells. Aspirin significantly attenuated the effect of ticagrelor.

The concentration of CD31 positive cells significantly increased 14 days after infarction (Fig. 9a and c). Both ticagrelor, aspirin and their combination, but not prasugrel, prevented the increase in CD31 concentration.

The number of CD105 positive cells decreased after infarction (Fig. 9a and d). Ticagrelor and aspirin equally attenuated the decrease. However, this effect was attenuated when ticagrelor and aspirin were combined. Prasugrel did not alter the number of CD105 positive cells.

The number of c-Kit positive cells increased 14 days after infarction (Fig. 10). Ticagrelor induced a further significant increase in c-Kit positive cells, whereas prasugrel and aspirin had no effect. Aspirin blocked the augmenting effect of ticagrelor.

Yet, immunofluorescent staining suggested co-localization of c-Kit with CD-31 in blood vessels and not in the cardiomyocytes (Fig. 10). 


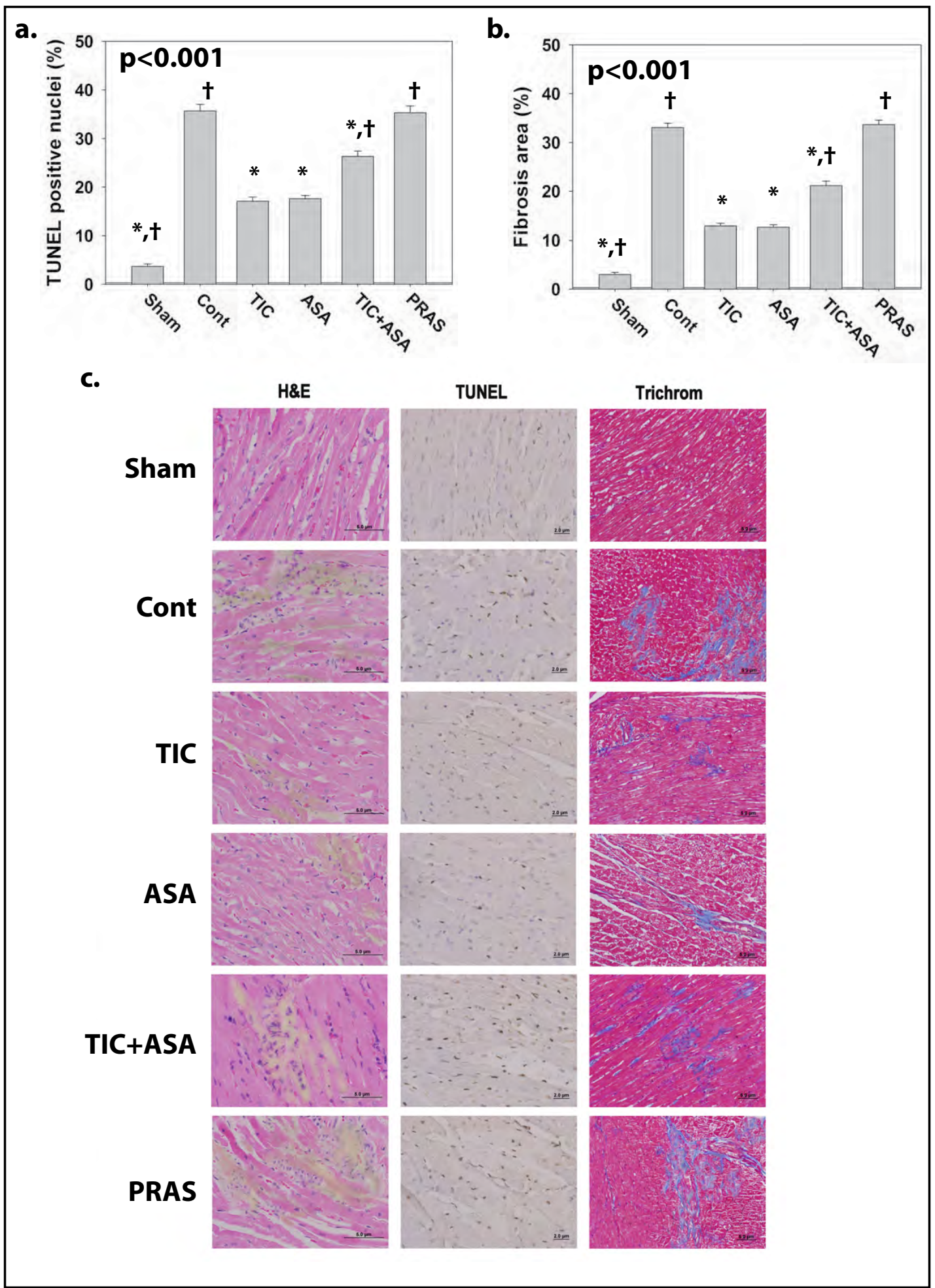

Fig. 7. a. Apoptosis (\% of TUNEL positive cells in the border zone of the infarct 14 days after infarction) $\left(\mathrm{n}=10\right.$ in each group). b. Fibrosis. ( $\mathrm{n}=8$ in each group) ${ }^{*} \mathrm{p}<0.001$ vs. Cont. $\dagger \mathrm{p}<0.001$ vs. TIC. c. Samples of H\&E, TUNEL (apoptosis) and TRICHROM (Fibrosis) staining of the myocardium at the border zone 14 days after infarction. ASA- aspirin; Cont- control; PRAS- prasugrel; TIC- ticagrelor. 


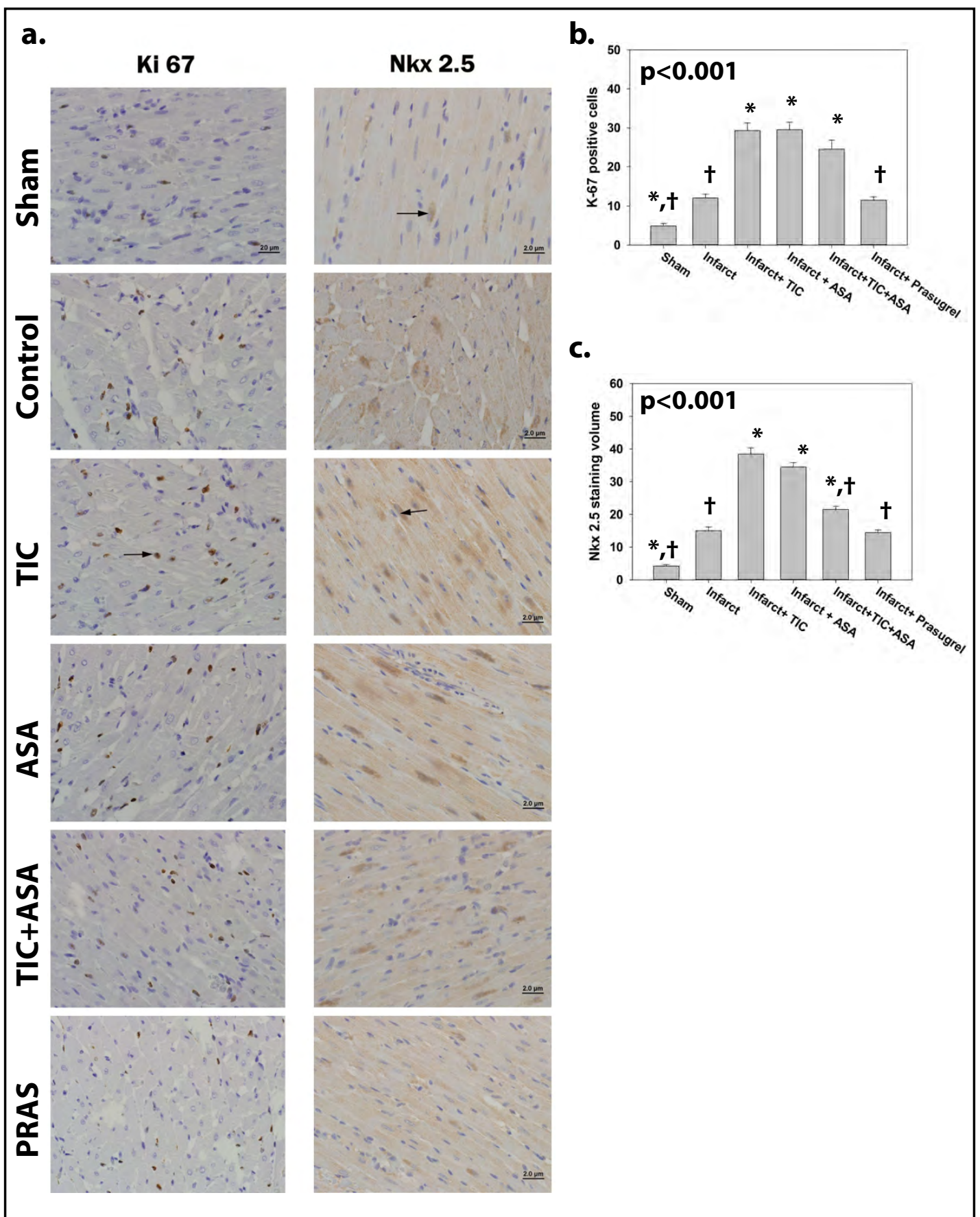

Fig. 8. a. Samples of myocardial staining for Ki67 and Nkx2.5 14 days after infarction. Arrows point to Ki 67 and Nkx2.5 positive cells, respectively. b. Number of K-67 positive cells ( $n=10$ in each group). c. Nkx2.5 staining volume. ${ }^{*} \mathrm{p}<0.018$ vs. Cont. $\dagger \mathrm{p}<0.001$ vs. TIC. ASA- aspirin; Cont- control; PRAS- prasugrel; TICticagrelor. 


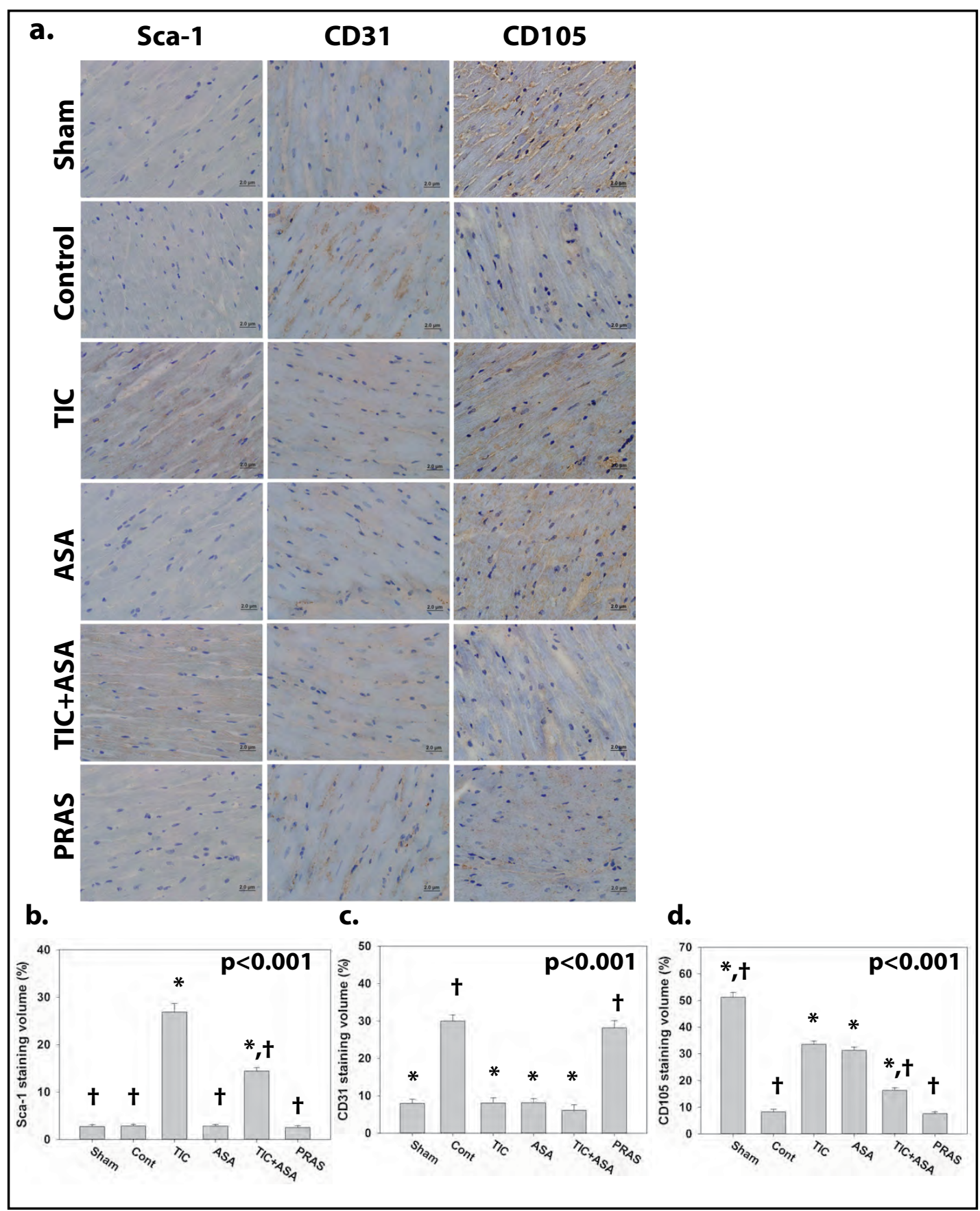

Fig. 9. a. Samples of myocardial staining for Sca-1, CD31 and CD105 14 days after infarction. b. Sca-1 staining volume. c. CD31 staining volume. D. CD105 staining volume ( $\mathrm{n}=10$ in each group). * $\mathrm{p}<0.001$ vs. Cont. $†$ p $<0.001$ vs. TIC. ASA- aspirin; Cont- control; PRAS- prasugrel; TIC- ticagrelor.

\section{Discussion}

The present study confirms that delayed exposure to ticagrelor can provide a long-term cardiac benefit, an effect that is independent of the acute cardioprotective effects. Initiating oral ticagrelor treatment 7 days after myocardial ischemia-reperfusion injury attenuated adverse remodeling and provided a sustained improvement in left ventricular systolic 


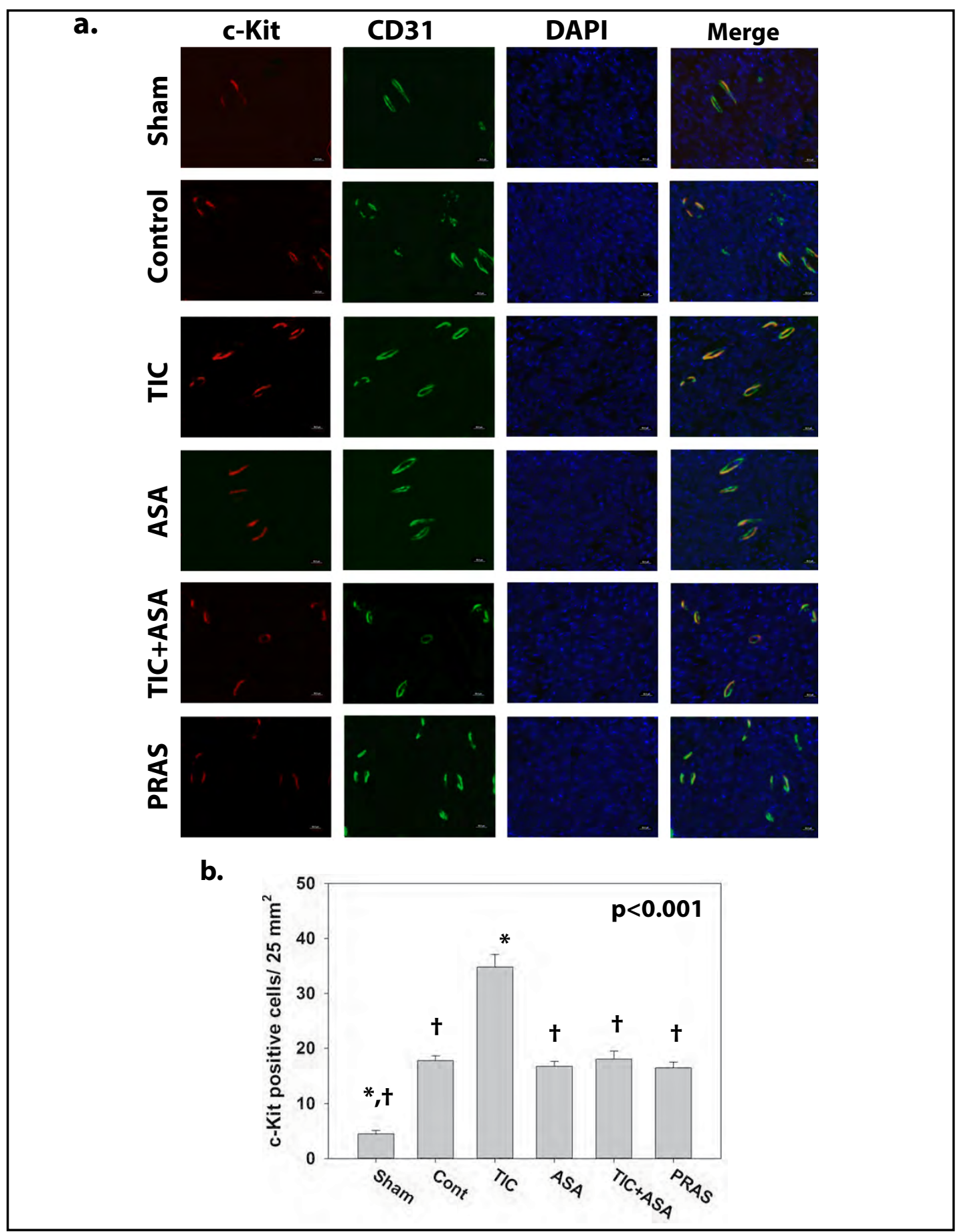

Fig. 10. a. Immunofluorescent staining of c-Kit and CD31 in samples from the border zone 14 days after infarction. There is co-localization of c-Kit and CD31 around blood vessels, but not in the myocardium. b. Number of c-Kit positive cells ( $\mathrm{n}=10$ in each group). ${ }^{*} \mathrm{p}<0.001$ vs. Cont. $\dagger \mathrm{p}<0.001$ vs. TIC. ASA- aspirin; Contcontrol; PRAS- prasugrel; TIC- ticagrelor.

function for 28 days. Aspirin had similar effects but when combined with ticagrelor, the protective effects were significantly attenuated, even though the effect on platelet aggregation of the combination group was preserved. Prasugrel, a third generation thienopyridine $\mathrm{P}_{2} \mathrm{Y}_{12}$ receptor antagonist had no effect on remodeling and heart function despite achieving similar 
degree of platelet inhibition indicating a platelet independent effect of ticagrelor. This is in line with our prior studies on the effects of these drugs on IS using a similar rodent model of ischemia reperfusion injury $[4,6,15]$.

At the doses used, ticagrelor, prasugrel and aspirin equally inhibited ADP-induced platelet aggregation. The combination of aspirin and ticagrelor resulted in insignificant augmentation of the effect compared to aspirin alone or ticagrelor alone. While aspirin does not directly affect the $\mathrm{P}_{2} \mathrm{Y}_{12}$ receptors, previous studies have also shown that aspirin inhibits ADP-induced platelet aggregation [16, 17]. As we have previously shown both ticagrelor and aspirin increase the production of 15-epi-lipoxin $\mathrm{A}_{4}$, an eicosanoid derived from arachidonic acid, with potent inflammation resolution properties $[4,6,15,18]$. However, when they are combined, the production of 15-epi-lipoxin $\mathrm{A}_{4}$ is blocked. Prasugrel, on the other hand, did not change 15-epi-lipoxin $\mathrm{A}_{4}$ levels. In the present study we show that ticagrelor, but not aspirin or prasugrel, increases myocardial concentrations of 6-keto-PGF ${ }_{1 \alpha}$, the stable metabolite of prostacyclin, and $\mathrm{PGE}_{2}$ in the remote, non-ischemic zone. Thus, it is plausible that the observed cardioprotective effects are partly mediated by the eicosanoids. However, the protective effects cannot only be attributed to anti-inflammatory properties, as CRP levels were equally reduced by the combination of ticagrelor and aspirin, whereas only the monotherapies had an impact on remodeling, fibrosis, and preservation of heart function.

Our prior data supports that the underlying cardioprotective mechanism of ticagrelor depends on activation of adenosine receptors by increased local extracellular adenosine levels, due to ticagrelor mediated inhibition of adenosine reuptake into the cells $[4,6,15$, $18,19]$. Adenosine in turn upregulate inducible nitric oxide synthase (iNOS) that activates cyclooxygenase-2 by S-nitrosylation [20,21]. S-nitrosylation of cyclooxygenase-2 leads to production of both $\mathrm{PGH}_{2}$, the precursor of prostaglandins, and 15-R-HETE, the precursor of 15-epi-lipoxin $\mathrm{A}_{4}$. Importantly, when S-nitrosylated cyclooxygenase-2 is acetylated by aspirin, the enzyme is completely inhibited. However, when a cyclooxygenase, that is not $\mathrm{S}$-nitrosylated, is acetylated by aspirin, it is activated to produce 15-R-HETE, but not $\mathrm{PGH}_{2}$ [20]. Prasugrel does not affect adenosine uptake and thus, does not alter the production of eicosanoids by cyclooxygenase- 2 .

In the failing hearts a shift from $\alpha$-myosin heavy chain (MHC) to $\beta$-MHC has been described $[22,23]$. Beta blockers increase the expression of $\alpha$-MHC after experimental myocardial infarction and improve remodeling [23]. In the present study only ticagrelor was able to increase the expression of $\alpha$-MHC. Unlike $\alpha$-MHC, both ticagrelor and aspirin alone, but not their combination, caused a similar attenuation of the increase in ANP, BNP, Collagen-I and Collagen-III mRNA levels. Again, prasugrel had no effect supporting a platelet independent mechanism.

As we found that ticagrelor and aspirin, but not their combination or prasugrel, started 7 days after infarction, improved remodeling, we assessed the effects of these therapies on the expression of markers of regeneration and stem cells. We found that both aspirin and ticagrelor, but not prasugrel, increased mRNA levels and cell expression of various markers of proliferation and progenitor and stem cells. However, there were several differences between the effects of aspirin and ticagrelor and more importantly, when combined, most of the effects were lost.

It has been reported that $\mathrm{c}-\mathrm{Kit}^{+}$cells are involved in early regenerative processes in neonatal (but not adult) mouse hearts, likely via a paracrine mechanism rather that direct cell implantation and transformation to cardiomyocytes [24]. The infarct in our model resulted in an insignificant increase in the mRNA levels of c-Kit ${ }^{+}$and a significant increase in the number of $\mathrm{c}-\mathrm{Kit}^{+}$positive cells in the heart tissue. Ticagrelor increased the expression of c-Kit ${ }^{+}$mRNA and the number of c-Kit ${ }^{+}$positive cells. This effect was blocked by aspirin. Immunofluorescent staining confirmed co-localization of c-Kit ${ }^{+}$and CD31 in blood vessel, in agreement with more recent studies reporting that $\mathrm{c}-\mathrm{Kit}^{+}$positive cells in the heart are endothelial in nature [25]. CD31 is a marker of endothelial cells and co-localization of c-Kit ${ }^{+}$ with CD31 has been previously reported [26]. Thus, our findings suggest that ticagrelor could affect angiogenesis post infarction. 
Sca-1 positive cells can be induced in vitro to express both endothelial cell and cardiomyocyte markers [27]. Increased Sca-1 staining and protein levels has been reported in the mouse heart 7 days after experimental infarction [27]. Transplantation of Sca-1 positive cells improved remodeling and heart function after infarction [27]. However, there is a controversy as to whether Sca-1 positive cells can be transformed to cardiomyocytes or mainly differentiate into endothelial cells $[28,29]$. Here we found that ticagrelor, but not aspirin or prasugrel increased the mRNA levels and staining intensity of Sca-1. Again, this effect was attenuated when aspirin was added to ticagrelor.

Ki-67 is a cell cycle marker that is specifically expressed in proliferating cells [30, 31]. For example, transplantation of adipose tissue mesenchymal cells conjugated with vascular endothelial growth factor (VEGF)-releasing micro-carriers increased the number of Ki-67 positive cells in the myocardium and improved left ventricular function after experimental myocardial infarction in the mice [32]. In the present study both ticagrelor and aspirin increased Ki-67 mRNA and the number of Ki-67 positive cells in the myocardium. Interestingly, combining ticagrelor and aspirin only partially attenuated the effect of each drug alone, even though they completely attenuated the increase in 15-epi-lipoxin $\mathrm{A}_{4}$ levels, suggesting that the effect of ticagrelor and aspirin on Ki-67 upregulation might be (partially) independent of 15-epi-lipoxin $\mathrm{A}_{4}$.

CD31, also known as Platelet Endothelial Cell Adhesion Molecule (PECAM-1), is found on the surface of monocytes, neutrophils, platelets and some T-cells. It is also expressed in the endothelial cell intercellular junctions [33]. It is involved in angiogenesis, leukocyte transmigration and integrin activation. A mild increase in the number of c-Kit + CD31 positive cells after experimental infarction has been reported [26]. Fibroblast growth factor-9 (FGF-9) significantly increased their number after experimental myocardial infarction in the non-diabetic and diabetic mouse, suggesting increased angiogenesis [26]. However, in our experiment, CD31 mRNA and protein staining significantly increased after infarction. Moreover, both ticagrelor and aspirin blocked the increase with similar effect of their combination, whereas prasugrel had no effect. As previously described, we found that c-Kit was co-localized with CD31 (see above).

CD34 is a phosphoglycoprotein that is found in hematopoietic stem cells [34]. CD34 positive cells can transform to cardiomyocytes [28]. We found that ticagrelor, but not aspirin or prasugrel, increased CD34 mRNA levels, an effect that was attenuated when combined with aspirin. Thus, our results suggest that ticagrelor augments the recruitment of hematopoietic stem cells.

CD105, also known as Endoglin, is a membrane glycoprotein, that plays a role in angiogenesis, and is located on cell surfaces as part of the TGF- $\beta$ receptor complex. Its expression is regulated during the development of the heart and endoglin deficient mice die due to cardiovascular abnormalities [35]. Multilineage differentiating stress-enduring (MUSE) cells express CD105, but not CD34, CD31, von Willebrand factor, and c-Kit, and are thus distinct from hematopoietic stem cells and endothelial precursor cells [36]. In experimental coronary artery ligation in the rat, levels of CD105 increase 3 days after infarction, then significantly decrease after 10 days and return to baseline after 17 days [37]. A similar pattern has been shown in patients after myocardial infarction as blood cell expression of MUSE CD105 positive cells increase on day 1 and 7 after infarction, compared to day 0 , and then return to baseline after 14 and 21 days [38]. The number of MUSE cells in the peripheral blood in the acute phase of infarction has been shown to correlate with improved left ventricular function over time [38]. It was reported that intracoronary administration of these cells improved remodeling in patients after myocardial infarction [39]. We, on the other hand, observed significant decrease in the CD105 mRNA levels and heart tissue staining 14 days after ischemia-reperfusion injury. Both ticagrelor and aspirin increased the levels. Again, when ticagrelor and aspirin were combined, the increase was attenuated.

The Nkx2.5 gene encodes a homeobox-containing transcription factor playing a role in heart formation and development. In our model, the staining of Nkx2.5 increased in the 
hearts 14 days after ischemia-reperfusion injury. Both ticagrelor and aspirin significantly increased the staining volume. However, when combined, the effect was significantly attenuated. Neonatal Nkx2.5 positive cardiomyoblasts can differentiate into functional cardiomyocytes as part of normal cardiac development [40]. Treating mice with granulocyte colony-stimulating factor in combination with stem cell factor after experimental ischemiareperfusion injury increased the number of Nkx2.5 positive cells in the infarcted zone and improved left ventricular function [41]. Li and Zhang transfected bone marrow mesenchymal stem cells (BMSCs) with Nkx2.5 and injected the cells to the periphery of myocardial infarction in rabbits. They reported that these cells were able to significantly enhance the ability to repair, and mitigate myocardial cells death, providing improved recovery [42]. Chen et al. reported that A83-01, a type 1 TGF $\beta$ receptor inhibitor, significantly increased the number of Nkx2.5 positive cardiomyoblasts at baseline and after myocardial injury in a mouse model of myocardial infarction. Treatment increased the number of newly formed cardiomyocytes, resulting in improved left ventricular elastance and stroke work [43]. On the other hand, Deutsch et al. concluded that myocardial infarction reactivates Nkx2.5 expression. However, the cells expressing Nkx2.5 resemble cardiofibroblasts and do not contribute to myogenesis [44].

Octamer-binding transcription factor 4 (Oct4) mediates pluripotency in embryonic stem cells and mesenchymal stem cells [45]. Cardiac differentiation of bone marrow stem cells was associated with downregulation of Oct4 expression $[46,47]$. Thus, the increase in Oct4 signifies recruitment of pluripotent stem cells.

Currently, we do not have effective therapies to prevent scar formation in the infarct zone, to attenuate progressive fibrosis and adverse remodeling of the non-infarcted zone after myocardial infarction [9]. Results from studies implanting various pluripotent and stem cells have been disappointing so far due to low engraftment and short survival of the transplanted cells [9-11]. There have been attempts to improve survival using various growth factors and RNA based therapy; however, significant breakthroughs have not been achieved $[9,10]$.

\section{Conclusion}

In conclusion, both ticagrelor and aspirin, started one week after experimental myocardial ischemia-reperfusion equally attenuated post-infarction adverse remodeling and preserved left ventricular systolic function in the rat, whereas prasugrel had no effect. However, when ticagrelor and aspirin were combined, the protective effect was lost. This effect cannot be attributed to the antiplatelet effects of the agents, as prasugrel had no effect despite providing equally effective platelet inhibition. As the combination of ticagrelor and aspirin reduced CRP levels to a similar extent as the monotherapies but had no cardioprotective effect, observed anti-inflammatory properties cannot fully explain the effects on remodeling and heart function. There were several important differences between ticagrelor and aspirin. While both equally reduced ANP, BNP, Collagen-I and Collagen-III levels, only ticagrelor increased $\alpha$-MHC mRNA levels. Moreover, only ticagrelor increased c-Kit, Sca-1 and CD34 mRNA levels and c-Kit, Ki-67 and Sca-1 protein levels. Although immunohistochemistry showed that ticagrelor and aspirin equally increased the number of Ki-67 positive cells, immunofluorescence staining suggested that only ticagrelor enhanced the number of cells positive for both c-Kit and CD31. We cannot exclude that some of the favorable effects of ticagrelor and aspirin are mediated by eicosanoids. Especially those effects that are attenuated when ticagrelor and aspirin are combined. However, further investigations are needed to establish direct cause and effect relations.

Our data support that ticagrelor, possibly by inducing a local increase in extracellular adenosine levels, can augment reparative mechanisms that 1) attenuate adverse remodeling and fibrosis and 2) increase cell proliferation and stem cell recruitment. Together this drives cardioprotection as evident by improved heart function and may provide an alternative 


\section{\begin{tabular}{ll} 
Cellular Physiology & Cell Physiol Biochem 2019:53:961-981 \\
\hline DOl: 10.33594/000000189 & 0 2019 The Author(s). Published by
\end{tabular}

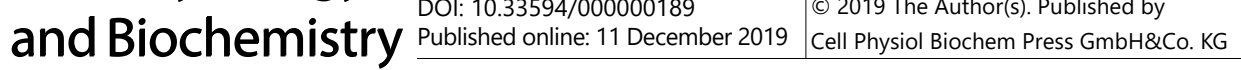 \\ Birnbaum et al.: Ticagrelor Improves Remodeling After Myocardial Infarction}

approach to stem cell therapy. As aspirin attenuated the cardioprotective effects of ticagrelor, our data challenges that added benefit of aspirin in combination with ticagrelor. There is a concern that numerous successful interventions in animal models of cardioprotection do not translate to meaningful benefit in the clinical setting [48]. Clearly, the rodent heart is more capable of regeneration compared to the human heart [24]. Thus, it is unclear whether the current effects can be replicated in the clinical setting. To what extent our findings translate to humans needs to be further explored in clinical studies.

\section{Disclosure Statement}

Dr. Nylander is an employee of AstraZeneca. Dr. Ye receives research grants from AstraZeneca and Boehringer Ingelheim. Dr. Yochai Birnbaum receives research grants from AstraZeneca.

\section{References}

1 Wallentin L, Becker RC, Budaj A, Cannon CP, Emanuelsson H, Held C, Horrow J, Husted S, James S, Katus H, Mahaffey KW, Scirica BM, Skene A, Steg PG, Storey RF, Harrington RA, Freij A, Thorsen M: Ticagrelor versus clopidogrel in patients with acute coronary syndromes. N Engl J Med 2009;361:1045-1057.

2 Cannon CP, Harrington RA, James S, Ardissino D, Becker RC, Emanuelsson H, Husted S, Katus H, Keltai M, Khurmi NS, Kontny F, Lewis BS, Steg PG, Storey RF, Wojdyla D, Wallentin L: Comparison of ticagrelor with clopidogrel in patients with a planned invasive strategy for acute coronary syndromes (PLATO): a randomised double-blind study. Lancet 2010;375:283-293.

3 Cattaneo M, Schulz R, Nylander S: Adenosine-mediated effects of ticagrelor: evidence and potential clinical relevance. J Am Coll Cardiol 2014;63:2503-2509.

4 Nanhwan MK, Ling S, Kodakandla M, Nylander S, Ye Y, Birnbaum Y: Chronic treatment with ticagrelor limits myocardial infarct size: an adenosine and cyclooxygenase-2-dependent effect. Arterioscler Thromb Vasc Biol 2014;34:2078-2085.

5 Vilahur G, Gutierrez M, Casani L, Varela L, Capdevila A, Pons-Llado G, Carreras F, Carlsson L, Hidalgo A, Badimon L: Protective Effects of Ticagrelor on Myocardial Injury After Infarction. Circulation 2016;134:1708-1719.

6 Ye Y, Birnbaum GD, Perez-Polo JR, Nanhwan MK, Nylander S, Birnbaum Y: Ticagrelor protects the heart against reperfusion injury and improves remodeling after myocardial infarction. Arterioscler Thromb Vasc Biol 2015;35:1805-1814.

7 Liu X, Gu Y, Liu Y, Zhang M, Wang Y, Hu L: Ticagrelor attenuates myocardial ischaemia-reperfusion injury possibly through downregulating galectin-3 expression in the infarct area of rats. Br J Clin Pharmacol 2018;84:1180-1186.

8 Vilahur G, Gutierrez M, Casani L, Lambert C, Mendieta G, Ben-Aicha S, Capdevila A, Pons-Llado G, Carreras F, Carlsson L, Hidalgo A, Badimon L: P2Y12 antagonists and cardiac repair post-myocardial infarction: global and regional heart function analysis and molecular assessments in pigs. Cardiovasc Res 2018;114:18601870.

9 Buja LM: Cardiac repair and the putative role of stem cells. J Mol Cell Cardiol 2019;128:96-104.

10 Micheu MM, Scarlatescu AI, Scafa-Udriste A, Dorobantu M: The Winding Road of Cardiac RegenerationStem Cell Omics in the Spotlight. Cells 2018;7:pii:E255.

11 Palmquist-Gomes P, Perez-Pomares JM, Guadix JA: Cell-based therapies for the treatment of myocardial infarction: lessons from cardiac regeneration and repair mechanisms in non-human vertebrates. Heart Fail Rev 2019;24:133-142.

12 Botker HE, Hausenloy D, Andreadou I, Antonucci S, Boengler K, Davidson SM, Deshwal S, Devaux Y, Di Lisa F, Di Sante M, Efentakis P, Femmino S, Garcia-Dorado D, Giricz Z, Ibanez B, Iliodromitis E, Kaludercic N, Kleinbongard P, Neuhauser M, Ovize M, et al.: Practical guidelines for rigor and reproducibility in preclinical and clinical studies on cardioprotection. Basic Res Cardiol 2018;113:39. 
13 Lindsey ML, Bolli R, Canty JM Jr., Du XJ, Frangogiannis NG, Frantz S, Gourdie RG, Holmes JW, Jones SP, Kloner RA, Lefer DJ, Liao R, Murphy E, Ping P, Przyklenk K, Recchia FA, Schwartz Longacre L, Ripplinger CM, Van Eyk JE, Heusch G: Guidelines for experimental models of myocardial ischemia and infarction. Am J Physiol Heart Circ Physiol 2018;314:H812-H838.

14 Ye Y, Bajaj M, Yang HC, Perez-Polo JR, Birnbaum Y: SGLT-2 Inhibition with Dapagliflozin Reduces the Activation of the Nlrp3/ASC Inflammasome and Attenuates the Development of Diabetic Cardiomyopathy in Mice with Type 2 Diabetes. Further Augmentation of the Effects with Saxagliptin, a DPP4 Inhibitor. Cardiovasc Drugs Ther 2017;31:119-132.

15 Birnbaum Y, Birnbaum GD, Birnbaum I, Nylander S, Ye Y: Ticagrelor and Rosuvastatin Have Additive Cardioprotective Effects via Adenosine. Cardiovasc Drugs Ther 2016;30:539-550.

16 Gan R, Teleg RA, Florento L, Bitanga ES: Effect of increasing doses of aspirin on platelet aggregation among stroke patients. Cerebrovasc Dis 2002;14:252-255.

17 Rinder CS, Student LA, Bonan JL, Rinder HM, Smith BR: Aspirin does not inhibit adenosine diphosphateinduced platelet alpha-granule release. Blood 1993;82:505-512.

18 Ye Y, Nylander S, Birnbaum Y: Unraveling the Interaction of Aspirin, Ticagrelor, and Rosuvastatin on the Progression of Atherosclerosis and Inflammation in Diabetic Mice. Cardiovasc Drugs Ther 2017;31:489500 .

19 van Giezen JJ, Sidaway J, Glaves P, Kirk I, Bjorkman JA: Ticagrelor inhibits adenosine uptake in vitro and enhances adenosine-mediated hyperemia responses in a canine model. J Cardiovasc Pharmacol Ther 2012;17:164-172.

20 Birnbaum Y, Ye Y, Lin Y, Freeberg SY, Huang MH, Perez-Polo JR, Uretsky BF: Aspirin augments 15-epi-lipoxin A4 production by lipopolysaccharide, but blocks the pioglitazone and atorvastatin induction of 15-epilipoxin A4 in the rat heart. Prostaglandins Other Lipid Mediat 2007;83:89-98.

21 Atar S, Ye Y, Lin Y, Freeberg SY, Nishi SP, Rosanio S, Huang MH, Uretsky BF, Perez-Polo JR, Birnbaum Y: Atorvastatin-induced cardioprotection is mediated by increasing inducible nitric oxide synthase and consequent S-nitrosylation of cyclooxygenase-2. Am J Physiol Heart Circ Physiol 2006;290:H1960-1968.

22 Miyata S, Minobe W, Bristow MR, Leinwand LA: Myosin heavy chain isoform expression in the failing and nonfailing human heart. Circ Res 2000;86:386-390.

23 Machackova J, Sanganalmath SK, Elimban V, Dhalla NS: beta-adrenergic blockade attenuates cardiac dysfunction and myofibrillar remodelling in congestive heart failure. J Cell Mol Med 2011;15:545-554.

24 Eschenhagen T, Bolli R, Braun T, Field LJ, Fleischmann BK, Frisen J, Giacca M, Hare JM, Houser S, Lee RT, Marban E, Martin JF, Molkentin JD, Murry CE, Riley PR, Ruiz-Lozano P, Sadek HA, Sussman MA, Hill JA: Cardiomyocyte Regeneration: A Consensus Statement. Circulation 2017;136:680-686.

25 Sultana N, Zhang L, Yan J, Chen J, Cai W, Razzaque S, Jeong D, Sheng W, Bu L, Xu M, Huang GY, Hajjar RJ, Zhou B, Moon A, Cai CL: Resident c-kit(+) cells in the heart are not cardiac stem cells. Nat Commun 2015;6:8701.

26 Singla D, Wang J: Fibroblast Growth Factor-9 Activates c-Kit Progenitor Cells and Enhances Angiogenesis in the Infarcted Diabetic Heart. Oxid Med Cell Longev 2016;2016:5810908.

27 Wang X, Hu Q Nakamura Y, Lee J, Zhang G, From AH, Zhang J: The role of the sca-1+/CD31- cardiac progenitor cell population in postinfarction left ventricular remodeling. Stem Cells 2006;24:1779-1788.

28 Mekala SR, Worsdorfer P, Bauer J, Stoll O, Wagner N, Reeh L, Loew K, Eckner G, Kwok CK, Wischmeyer E, Dickinson ME, Schulze H, Stegner D, Benndorf RA, Edenhofer F, Pfeiffer V, Kuerten S, Frantz S, Ergun S: Generation of Cardiomyocytes From Vascular Adventitia-Resident Stem Cells. Circ Res 2018;123:686-699.

29 Vagnozzi RJ, Sargent MA, Lin SJ, Palpant NJ, Murry CE, Molkentin JD: Genetic Lineage Tracing of Sca-1(+) Cells Reveals Endothelial but Not Myogenic Contribution to the Murine Heart. Circulation 2018;138:29312939.

30 Scholzen T, Gerdes J: The Ki-67 protein: from the known and the unknown. J Cell Physiol 2000;182:311322.

31 Cuylen S, Blaukopf C, Politi AZ, Muller-Reichert T, Neumann B, Poser I, Ellenberg J, Hyman AA, Gerlich DW: Ki-67 acts as a biological surfactant to disperse mitotic chromosomes. Nature 2016;535:308-312.

32 Madonna R, Petrov L, Teberino MA, Manzoli L, Karam JP, Renna FV, Ferdinandy P, Montero-Menei CN, YlaHerttuala S, De Caterina R: Transplantation of adipose tissue mesenchymal cells conjugated with VEGFreleasing microcarriers promotes repair in murine myocardial infarction. Cardiovasc Res 2015;108:39-49. 
33 Fernandes S, Naumova AV, Zhu WZ, Laflamme MA, Gold J, Murry CE: Human embryonic stem cell-derived cardiomyocytes engraft but do not alter cardiac remodeling after chronic infarction in rats. J Mol Cell Cardiol 2010;49:941-949.

34 Tindle RW, Nichols RA, Chan L, Campana D, Catovsky D, Birnie GD: A novel monoclonal antibody BI-3C5 recognises myeloblasts and non-B non-T lymphoblasts in acute leukaemias and CGL blast crises, and reacts with immature cells in normal bone marrow. Leuk Res 1985;9:1-9.

35 Sanz-Rodriguez F, Guerrero-Esteo M, Botella LM, Banville D, Vary CP, Bernabeu C: Endoglin regulates cytoskeletal organization through binding to ZRP-1, a member of the Lim family of proteins. J Biol Chem 2004;279:32858-32868.

36 Kuroda Y, Kitada M, Wakao S, Dezawa M: Bone marrow mesenchymal cells: how do they contribute to tissue repair and are they really stem cells? Arch Immunol Ther Exp (Warsz) 2011;59:369-378.

37 Orbay H, Zhang Y, Valdovinos HF, Song G, Hernandez R, Theuer CP, Hacker TA, Nickles RJ, Cai W: Positron emission tomography imaging of CD105 expression in a rat myocardial infarction model with (64)CuNOTA-TRC105. Am J Nucl Med Mol Imaging 2013;4:1-9.

38 Tanaka T, Nishigaki K, Minatoguchi S, Nawa T, Yamada Y, Kanamori H, Mikami A, Ushikoshi H, Kawasaki M, Dezawa M, Minatoguchi S: Mobilized Muse Cells After Acute Myocardial Infarction Predict Cardiac Function and Remodeling in the Chronic Phase. Circ J 2018;82:561-571.

39 Schachinger V, Assmus B, Erbs S, Elsasser A, Haberbosch W, Hambrecht R, Yu J, Corti R, Mathey DG, Hamm CW, Tonn T, Dimmeler S, Zeiher AM, investigators R-A: Intracoronary infusion of bone marrow-derived mononuclear cells abrogates adverse left ventricular remodelling post-acute myocardial infarction: insights from the reinfusion of enriched progenitor cells and infarct remodelling in acute myocardial infarction (REPAIR-AMI) trial. Eur J Heart Fail 2009;11:973-979.

40 Serpooshan V, Liu YH, Buikema JW, Galdos FX, Chirikian O, Paige S, Venkatraman S, Kumar A, Rawnsley DR, Huang X, Pijnappels DA, Wu SM: Nkx2.5+ Cardiomyoblasts Contribute to Cardiomyogenesis in the Neonatal Heart. Sci Rep 2017;7:12590.

41 Kanellakis P, Slater NJ, Du XJ, Bobik A, Curtis DJ: Granulocyte colony-stimulating factor and stem cell factor improve endogenous repair after myocardial infarction. Cardiovasc Res 2006;70:117-125.

42 Li P, Zhang L: Exogenous Nkx2.5- or GATA-4-transfected rabbit bone marrow mesenchymal stem cells and myocardial cell co-culture on the treatment of myocardial infarction in rabbits. Mol Med Rep 2015;12:2607-2621.

43 Chen WP, Liu YH, Ho YJ, Wu SM: Pharmacological inhibition of TGFbeta receptor improves Nkx2.5 cardiomyoblast-mediated regeneration. Cardiovasc Res 2015;105:44-54.

44 Deutsch MA, Doppler SA, Li X, Lahm H, Santamaria G, Cuda G, Eichhorn S, Ratschiller T, Dzilic E, Dressen M, Eckart A, Stark K, Massberg S, Bartels A, Rischpler C, Gilsbach R, Hein L, Fleischmann BK, Wu SM, Lange $\mathrm{R}$, Krane M: Reactivation of the Nkx2.5 cardiac enhancer after myocardial infarction does not presage myogenesis. Cardiovasc Res 2018;114:1098-1114.

45 Garikipati VNS, Singh SP, Mohanram Y, Gupta AK, Kapoor D, Nityanand S: Isolation and characterization of mesenchymal stem cells from human fetus heart. PLoS One 2018;13:e0192244.

46 Lu T, Pelacho B, Hao H, Luo M, Zhu J, Verfaillie CM, Tian J, Liu Z: Cardiomyocyte differentiation of rat bone marrow multipotent progenitor cells is associated with downregulation of Oct-4 expression. Tissue Eng Part A 2010;16:3111-3117.

47 Shi ST, Wu XX, Hao W, Wang X, Miao HT, Zhen L, Nie SP: Triiodo-L-Thyronine Promotes the Maturation of Cardiomyocytes Derived From Rat Bone Marrow Mesenchymal Stem Cells. J Cardiovasc Pharmacol 2016;67:388-393.

48 Heusch G: Critical Issues for the Translation of Cardioprotection. Circ Res 2017;120:1477-1486. 